\title{
Study on the polymorphism of POU1F1 gene in sheep
}

\author{
Jun Yan Bai ${ }^{1}$, Xu Wang ${ }^{1}$, You Bing Yang ${ }^{1}$, Xiao Hui Zhang ${ }^{1}$, You Zhi Pang ${ }^{1}$, Hong Wei Li ${ }^{1}$
}

${ }^{1}$ Henan University of Science and Technology, College of Animal Science and Technology, Luoyang, Henan, China.

ABSTRACT - In this study, POU1F1 gene polymorphism was detected in five sheep populations (large-tailed Han, small-tailed Han, Yuxi fat-tailed, Lanzhou large-tailed, and Mongolian sheep), using DNA pooling and sequencing, to provide theoretical basis for the breeding of excellent sheep varieties. Three single-nucleotide polymorphism (SNP) loci of POU1F1 gene were detected in five sheep populations, namely C355T $(\mathrm{C} / \mathrm{T}), \mathrm{C} 71 \mathrm{G}(\mathrm{C} / \mathrm{G})$, and $\mathrm{C} 330 \mathrm{G}(\mathrm{C} / \mathrm{G})$. C and T frequencies of C355T were $0.67 / 0.33,0.81 / 0.19,0.67 / 0.33,1.00 / 0.00$, and 0.93/0.07, respectively, in large-tailed Han, small-tailed Han, Yuxi fat-tailed, Mongolian, and Lanzhou large-tailed sheep. C of C355T locus was the dominant allele in five sheep populations. $\mathrm{C}$ and $\mathrm{G}$ allele frequencies of $\mathrm{C} 330 \mathrm{G}$ locus were detected in Yuxi fat-tailed sheep; their frequencies were 0.75 and 0.25 , respectively. $\mathrm{C}$ and $\mathrm{G}$ allele of $\mathrm{C} 71 \mathrm{G}$ locus were only detected in Yuxi fat-tailed and large-tailed Han sheep; their frequencies were $0.87 / 0.13$ and 0.87/0.13, respectively. The cluster analysis based on POU1F1 gene sequence showed that bactrian camel, dromedary, and wild camel clustered first, and dolphin and killer whales clustered according to taxonomy. Although the four species Tibetan antelope, buffalo, goat, and sheep were alone, they got close and the relative genetic relationship was intimate according to the dendrogram. The mutation site analysis of the POU1F1 gene in five sheep populations in this study would be favorable for uncovering the function of POU1F1 gene deeply.

Key Words: DNA pooling, phylogenetic tree, sheep, SNP

\section{Introduction}

Pituitary specific transcriptional factor (POU1F1/Pit-1), Oet-1, and Uric-86 belonged to the same protein family, namely POU protein cluster. They were named as the first letters of three nuclear transcription factors, including Pit, Oct, and Unc, respectively (Rosenfeld, 1991). POU1F1 protein had three important structural domains: N-terminal transcriptional activation domain (mainly the first, second, and third exon codes of POU1F1 gene), POU specific region (mainly the third and fourth exon codes of POU1Fl gene), and POU homologous region (mainly the fifth and sixth exon codes of POU1F1 gene). POU1F1 was mainly expressed in the anterior pituitary cells. Its main function was to regulate cell differentiation and animal growth and development. It could recognize specific gene sequence and combine with it, resulting in intracellular gene transcription, transcription and expression of growth hormone, prolactin, and thyroid stimulating hormone B cell gene in anterior pituitary gland, thus affecting animal growth, development,

Received September 2, 2015 and accepted January 21, 2016.

Corresponding author: junyanb@163.com

http://dx.doi.org/10.1590/S1806-92902016001000004

Copyright (C) 2016 Sociedade Brasileira de Zootecnia. This is an Open Access article distributed under the terms of the Creative Commons Attribution License (http://creativecommons.org/licenses/by/4.0/), which permits unrestricted use, distribution, and reproduction in any medium, provided the original work is properly cited. and reproduction. In view of the important function of POUlF1 gene, POU1F1 gene was studied in pig (Brunsch et al., 2002), cattle (Liu et al., 2005), chicken (Qiu et al., 2006), goat (Lan et al., 2007; Wang, 2008), and other animals. Woollard et al. (2000) reported the sixth exon genetic variation locus of POU1F1 gene in cattle for the first time and Hinf I restriction digestion polymorphism produced; Bastos et al. (2006) showed that one A-G mutation existed in POU1F1 gene intron in sheep. However, there are few reports on POU1F1 gene in sheep. Therefore, in the present study, POU1F1 gene polymorphism was detected in five sheep populations (large-tailed Han, small-tailed Han, Yuxi fat-tailed, Lanzhou large-tailed, and Mongolian sheep), using DNA pooling and sequencing, to provide theoretical basis for the breeding of excellent sheep varieties.

\section{Material and Methods}

Thirty large-tailed Han sheep, 30 small-tailed Han sheep, 30 Mongolian sheep, 30 Lanzhou large-tailed sheep, and 30 Yuxi fat-tailed sheep were selected. Two milliliters of blood were collected from the vein of each sheep. The blood was fully mixed with ACD anticoagulant, rapidly transported to the laboratory at low temperature, and stored at $-20{ }^{\circ} \mathrm{C}$ in a refrigerator.

DNA was extracted with blood genomic DNA extraction kit. Its purity was detected by $1 \%$ agarose gel 
electrophoresis. It was preserved at $-20{ }^{\circ} \mathrm{C}$. DNA pool was constructed using the method of Li et al. (2011): after some individual DNA with the same characteristics was quantified and diluted, the constructed DNA was called DNA pool according to balanced mix.

The primer sequences of POU1F1 gene was obtained from Luo et al. (2011). The primers were synthesized by Beijing Dingguo Changsheng Biotechnology Co., Ltd. (Table 1).

DNA pool PCR products of five sheep breeds were cut, recovered, and purified. The sample was sent to Beijing Qingke Xinye Biotechnology Co., Ltd. for sequencing.

According to Cui et al. (2005), the corresponding peaks of all SNP alleles in Chromas.exe of Mwsnap software were obtained, and the gene frequency was estimated according to the formula below:

$$
\mathrm{f}_{1}=\mathrm{h}_{\mathrm{i}} /\left(\mathrm{h}_{1}+\mathrm{h}_{2}\right), \quad(\mathrm{i}=1,2)
$$

In the formula, $f_{1}$ showed the allele frequency at a certain SNP site; and $h_{1}$ and $h_{2}$ showed the peak of SNP alleles 1 and 2 in the sequencing map.

The homologous comparison of POU1F1 gene sequence in sheep was performed using blast module in NCBI. The phylogenetic tree of POU1F1 gene sequences of different species were drawn using MegAlign module in DNAStar software.

\section{Results}

The gradient PCR amplification was performed on POU1F1 gene, so as to seek the optimal annealing temperature of POU1F1 gene. The gradient PCR core temperature was $53.5^{\circ} \mathrm{C}$ and the range was $\pm 5^{\circ} \mathrm{C}$. Twelve $(1,2,3,4,5,6,7,8,9,10,11$, and 12) sample application holes corresponded to 12 annealing temperatures on

Table 1 - Relational information for POU1F1 gene

\begin{tabular}{llcc}
\hline Gene & \multicolumn{1}{c}{$\begin{array}{c}\text { Primer sequence } \\
(5, \rightarrow 3,)\end{array}$} & $\begin{array}{c}\text { AT } \\
\left({ }^{\circ} \mathrm{C}\right)\end{array}$ & $\begin{array}{c}\text { Fragment size } \\
(\mathrm{bp})\end{array}$ \\
\hline POU1F1 F: CCATCATCTCCCTTCTT & & \\
& R: AATGTACAATGTCCTTCTGAG & 58.10 & 457 \\
\hline
\end{tabular}

AT - annealing temperature. the agarose gel plate. The temperatures of the 12 holes were $47.9,48.6,49.4,50.2,51.3,52.3,53.5,54.6,55.8$, $56.7,57.6$, and $58.1{ }^{\circ} \mathrm{C}$, respectively. When the annealing temperature was relatively low $\left(47.9 \sim 55.8^{\circ} \mathrm{C}\right)$, the impurity bands containing target band were amplified in POU1F1 gene (Figure 1). The target band was impure. The annealing temperature with single target band was chosen as the annealing temperature of POU1F1 gene, so the optimal annealing temperature of POU1F1 gene was $58.1^{\circ} \mathrm{C}$ in the study.

Three obvious SNP mutation loci of POU1F1 gene were detected in five sheep populations including largetailed Han, small-tailed Han, Yuxi fat-tailed, Lanzhou large-tailed, and Mongolian sheep. They were C355T site $(\mathrm{C} / \mathrm{T}), \mathrm{C} 71 \mathrm{G}$ site $(\mathrm{C} / \mathrm{G})$, and $\mathrm{C} 330 \mathrm{G}$ site $(\mathrm{C} / \mathrm{G})$, respectively (Figures 2, 3, and 4).

$\mathrm{C}$ allele frequency and $\mathrm{T}$ allele frequency of $\mathrm{C} 355 \mathrm{~T}$ site in large-tailed Han, small-tailed Han, Yuxi fat-tailed, Mongolian, and Lanzhou large-tailed Han sheep were $0.67 / 0.33,0.81 / 0.19,0.67 / 0.33,1.00 / 0.00$, and $0.93 / 0.07$, respectively (Table 2). C allele frequency of C355T site

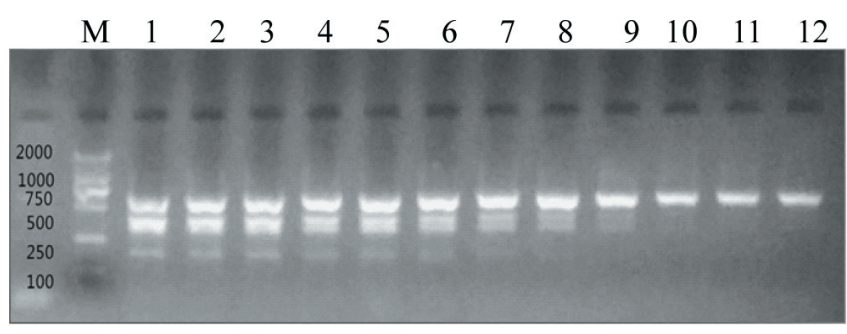

M - Marker DL2000,1, 2, 3, 4, 5, 6, 7, 8, 9, 10,11, and 12 corresponding annealing temperatures were $47.9,48.6,49.4,50.2,51.3,52.3,53.5,54.6,55.8,56.7,57.6$, and $58.1^{\circ} \mathrm{C}$, respectively.

Figure 1 - Gradient PCR amplification products of POU1F1 gene.

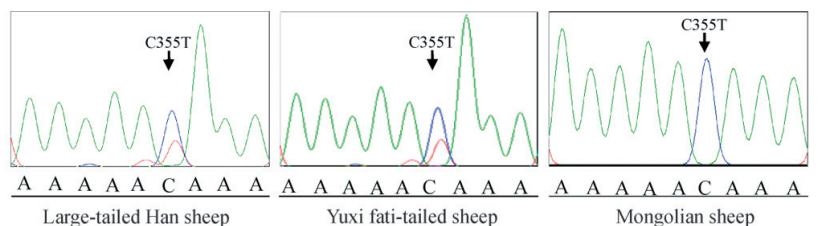

Figure 2 - C355T sites of POU1F1 gene in sheep.

Table 2 - SNP allele frequency of POU1F1 gene in five sheep breeds

\begin{tabular}{|c|c|c|c|c|c|c|}
\hline Site & Large-tailed Han sheep & Small-tailed Han sheep & Yuxi fat-tailed sheep & Mongolian sheep & Lanzhou large-tailed sheep & SNP \\
\hline $\mathrm{C} 71 \mathrm{G}$ & $\begin{array}{l}\mathrm{G}(0.13) \\
\mathrm{C}(0.87)\end{array}$ & $\begin{array}{l}\mathrm{G}(0.00) \\
\mathrm{C}(1.00)\end{array}$ & $\begin{array}{l}\mathrm{G}(0.13) \\
\mathrm{C}(0.87)\end{array}$ & $\begin{array}{l}\mathrm{G}(0.00) \\
\mathrm{C}(1.00)\end{array}$ & $\begin{array}{l}\mathrm{G}(0.00) \\
\mathrm{C}(1.00)\end{array}$ & $\begin{array}{l}\mathrm{G}(0.00) \\
\mathrm{C}(1.00)\end{array}$ \\
\hline C330G & $\begin{array}{l}\mathrm{G}(0.00) \\
\mathrm{C}(1.00)\end{array}$ & $\begin{array}{l}\mathrm{G}(0.00) \\
\mathrm{C}(1.00)\end{array}$ & $\begin{array}{l}G(0.25) \\
C(0.75)\end{array}$ & $\begin{array}{l}\mathrm{G}(0.00) \\
\mathrm{C}(1.00)\end{array}$ & $\begin{array}{l}\mathrm{G}(0.00) \\
\mathrm{C}(1.00)\end{array}$ & $\begin{array}{l}\mathrm{G}(0.00) \\
\mathrm{C}(1.00)\end{array}$ \\
\hline C355T & $\begin{array}{l}\mathrm{T}(0.33) \\
\mathrm{C}(0.67)\end{array}$ & $\begin{array}{l}\mathrm{T}(0.19) \\
\mathrm{C}(0.81)\end{array}$ & $\begin{array}{l}\mathrm{T}(0.33) \\
\mathrm{C}(0.67)\end{array}$ & $\begin{array}{l}\mathrm{T}(0.00) \\
\mathrm{C}(1.00)\end{array}$ & $\begin{array}{l}\mathrm{T}(0.07) \\
\mathrm{C}(0.93)\end{array}$ & $\begin{array}{l}\mathrm{C}(0.00) \\
\mathrm{T}(1.00)\end{array}$ \\
\hline
\end{tabular}

SNP - single-nucleotide polymorphism. 
was the dominant allele in five sheep populations. $\mathrm{C}$ allele frequency and $\mathrm{G}$ allele frequencies of $\mathrm{C} 330 \mathrm{G}$ site were detected in Yuxi fat-tailed sheep. Their frequencies were 0.75 and 0.25 , respectively. C allele was only detected in large-tailed Han, small-tailed Han, Mongolia, and Lanzhou large-tailed sheep; its frequency was 1.00. Only $\mathrm{C}$ alleles and $\mathrm{G}$ alleles of $\mathrm{C} 71 \mathrm{G}$ site were detected in Yuxi fat-tailed and large-tailed Han sheep. Their frequencies were 0.87/0.13 and $0.87 / 0.13$, respectively. Only $\mathrm{C}$ allele was detected in small-tailed Han, Mongolia, and Lanzhou large-tailed sheep; its frequency was 1.00 .

POU1F1 gene sequence in small-tailed Han sheep was compared with NCBI web site. The results showed that POU1F1 gene sequences in small-tailed Han sheep had 99\% similarity with sheep POU1F1 gene, and also had higher similarity with those of goat, buffalo, yak, Tibetan antelope, horse, bactrian camel, and other livestock. The phylogenetic tree of POU1F1 gene sequences in different species was established using DNAStar software (Figure 5).

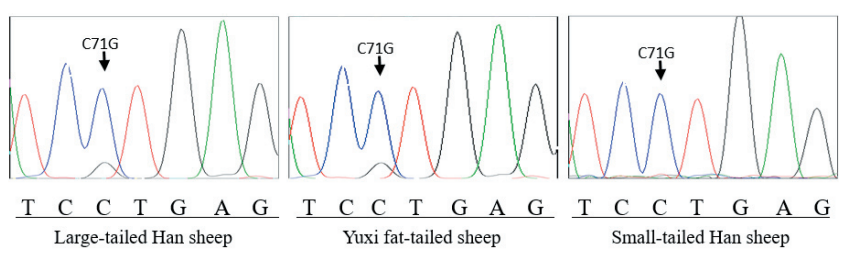

Figure 3 - C71G sites of POU1F1 gene in sheep.

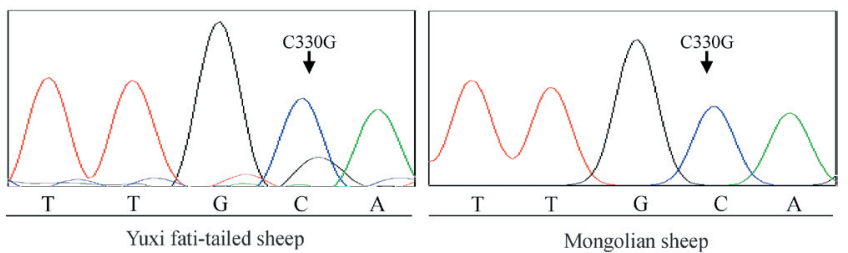

Figure 4 - C330G sites of POU1F1 gene in sheep.

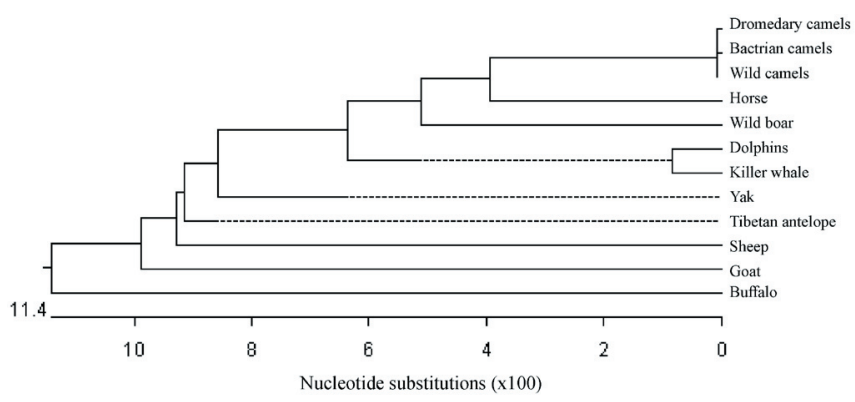

Figure 5 - Different species of tree POU1F1 gene system development.
Bactrian camels, dromedary, and wild camel clustered first; dolphins and killer whales were clustered according to taxonomy. Although four species - Tibetan antelope, buffalo, goat, and sheep - were separated, they still got close and the relative genetic relationship was intimate according to the dendrogram.

\section{Discussion}

The genomic GC content was about $40 \% \sim 45 \%$ in vertebrate. However, the GC was not averagely distributed in the genome. Their contents in some DNA fragments reached as high as $60 \%$, and only about $33 \%$ in other regions (Sueoka, 1962); namely, vertebrate genome was the chimera of rich-GC region and poor-GC region (Bernardi et al., 1985). The difference between GC contents played an important role in gene expression regulation and gene mutation (Bernardi et al., 1988). In this experiment, the important characteristic of POU1F1 gene base composition in sheep was that GC content was poor, only reaching $39.61 \%$, and annealing temperature was only $60.39 \%$, suggesting that sheep POU1F1 gene was located in the poor-GC homogeneous region. Further studies are still required on whether the base composition deviation was closely related to the gene function.

POU structure was an important transcriptional regulatory structure. Researchers have conducted many studies on cattle, pig, sheep, and other animals. Sun (2007) studied the effect of POU1F1 gene on Liangshan semi-fine wool sheep weight trait, with results showing that the gene had a significant influence on birth weight and weight at 1.5 years old. Luo et al. (2011) studied the correlativity of POU1F1 gene T58C and T172G same-sense mutation on goat populations of synonymous mutations on the body measurement and carcass traits. The result showed that the carcass weight, dressing percentage, eye muscle area, and lumbar muscle thickness in Smallxiang Aa genotype goat population in the southeast of Guizhou were significantly lower than those of AA and aa genotypes $(\mathrm{P}<0.05)$. Carcass weight, dressing percentage, eye muscle area, lumbar muscle thickness, net meat weight, meat factor, and and bone weight in $\mathrm{T} 172 \mathrm{C}$ locus $\mathrm{BB}$ genotype population were significantly lower than those of $\mathrm{Bb}$ and $\mathrm{bb}$ genotypes $(\mathrm{P}<0.05)$. The correlation analysis was studied between the mutation locus and reproductive traits in sheep.

\section{Conclusions}

The POU1F1 gene is important for animal growth, development, and reproduction. The mutation site analysis 
of the POU1F1 gene in five sheep populations in this study would be favorable for uncovering the function of POU1F1 gene deeply.

\section{Acknowledgments}

This study was supported by the National Natural Science Foundation of China (31201777).

\section{References}

Bastos, E.; Santos, I.; Parentier, I. H.; Castrillo, J. L.; Cravador, A.; Guedes-Pinto, H. and Renaville, R. 2006. Ovis aries Pit-I gene: cloning characterization and polymorphism analysis. Genetica 126:303-314

Bernardi, G.; Mounchiround, D.; Gautier, C. and Bernardi, G. 1988. Compositional patterns in vertebrate genomes: Conservation and change in evolution. Journal of Molecular Evolution 28:7-18.

Bernardi, G.; Olofsson, B.; Filipski, J.; Zerial, M.; Salinas, J.; Cuny, G.; Meunie-Rotival, M. and Rodier, F. 1985. The mosaic genome of warm-blooded vertebrates. Science 228:953-958.

Brunsch, C.; Sternstein, I.; Reinecke, P. and Bieniek, J. 2002. Analysis of associations of PITl genotypes with growth, meat quality and carcass composition traits in pigs. Journal of Applied Genetics 43:85-91.

Cui, J. X.; Du, H. L. and Zhang, X. Q. 2005. Rapidly screening SNPs and estimating allelic frequencies by DNA pooling and sequencing. Acta Genetica Sinica 32:372-377.

Lan, X. Y.; Pan, C. Y.; Chen, H.; Lei, C. Z.; Hua, L. S.; Yang, X. B. and Qiu, G. Y. 2007. Ddel polymorphism in coding region of goat
POU1F1 gene and its association with production traits. AsianAustralian Journal of Animal Science 20:1342-1348.

Li, J. R.; Ding, Y. H.; Zhang, Y. L.; Wang, B. R. and Liu, R. Y. 2011. Rapidly screening SNPs and estimating allelic frequencies by DNA pooling and sequencing. Animal Husbandry \& Veterinary Medicine 43:17-19.

Liu, B.; Chen, H.; Lan, X. Y.; Lei, C. Z.; Zhang, Z. Q. and Zhang, R. F. 2005. Correlation of polymorphisms of POU1 F1 gene and growth traits in Qinchuan cattle and its hybrid cattle. Scientia Agricultura Sinica 38:2520-2525.

Luo, W. X.; Cai, H. F.; Wang, X. Q. and Liu, R. Y. 2011. Relationship between polymorphism of PoUIFl gene and slaughter traits of goat. China Animal Husbandry Journal 47:05-08.

Qiu, F. F.; Nie, Q. H.; Jin, W. G.; Yang, J. H.; Lin, S. M.; Sun, H. and Zhang, X. Q. 2006. Association of a $57 \mathrm{bp}$ indel in chicken PIT-1 gene with growth and carcass traits. Acta Agriculturae Universitatis Jiangxiensis 28:284-299.

Rosenfeld, M. G. 1991. POU-domain transcription factors: Powerful developmental regulators. Genes \& Development 5:897-907.

Sueoka, N. 1962. On the genetic basis of variation and heterogeneity of DNA base composition. Proc. Natl. Acad. Sci. USA 48:582-592.

Sun, L. P. 2007. Study on sheep POU1F1 gene polymorphism and body weight traits in Liangshan semi fine wool sheep. Master thesis. Sichuan Agricultural University, Chengdu.

Wang, X. Q. 2008. Relationship between the gene polymorphism of pituitary transcription factor (POU1F1) and its correlation with slaughter traits in goats. Master thesis. Guizhou Agricultural University, Guiyang.

Woollard, J.; Poncede, L. F. A. and Tuggle, C. K. A. 2000. Rapid communication: Localization of POU1F1 to bovine and caprine 1q21-22. Animal Science 78:242-243. 